
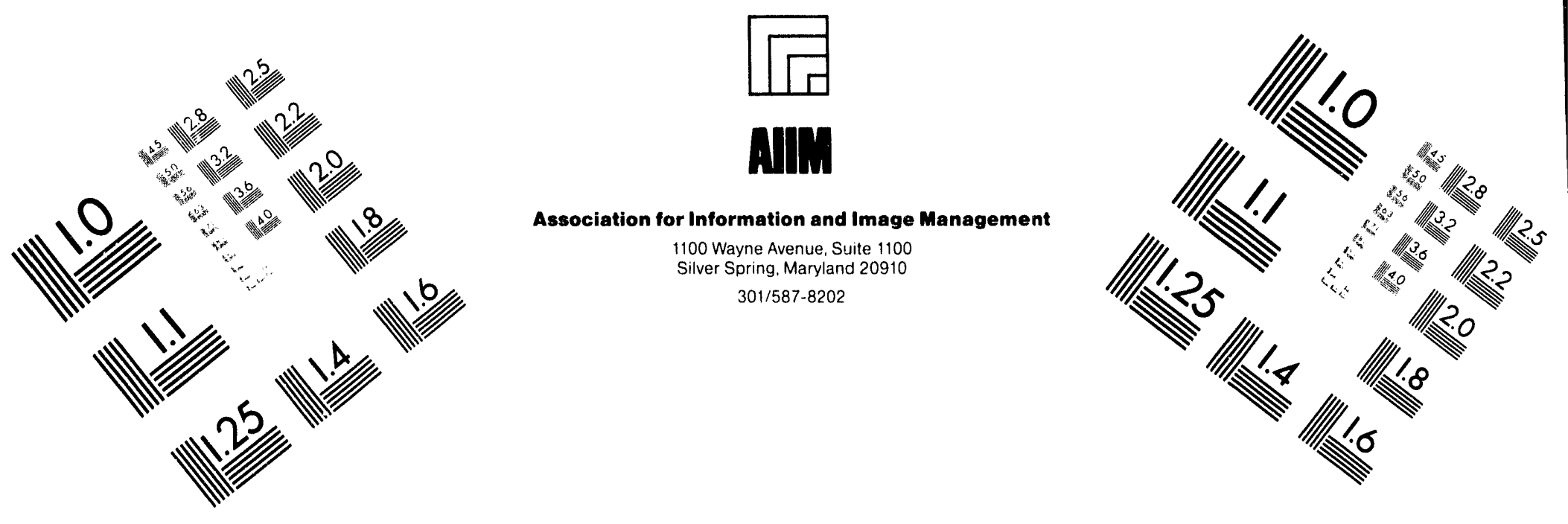

\title{
Centimeter
}

2
2 Inches

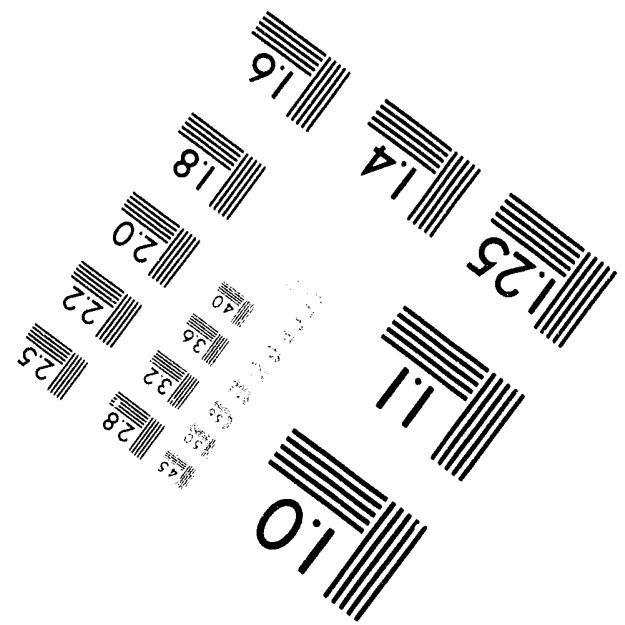

MANUFACTURED TO AIIM STANDARDS

BY APPLIED IMAGE. INC.

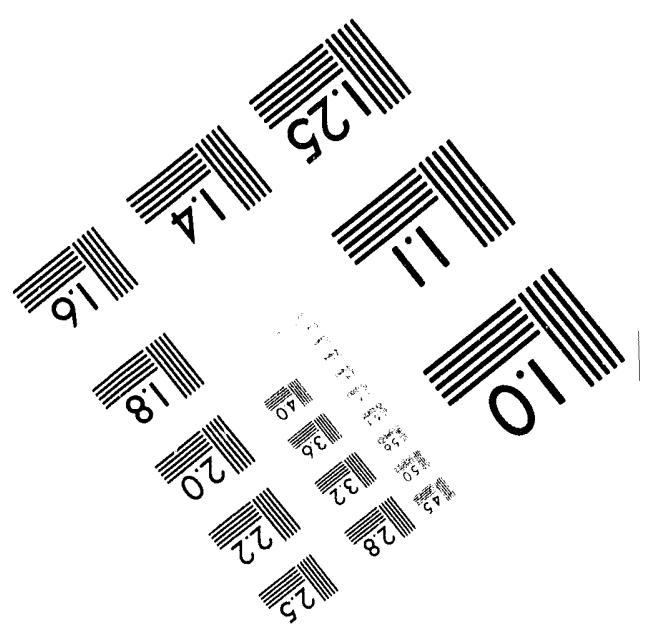



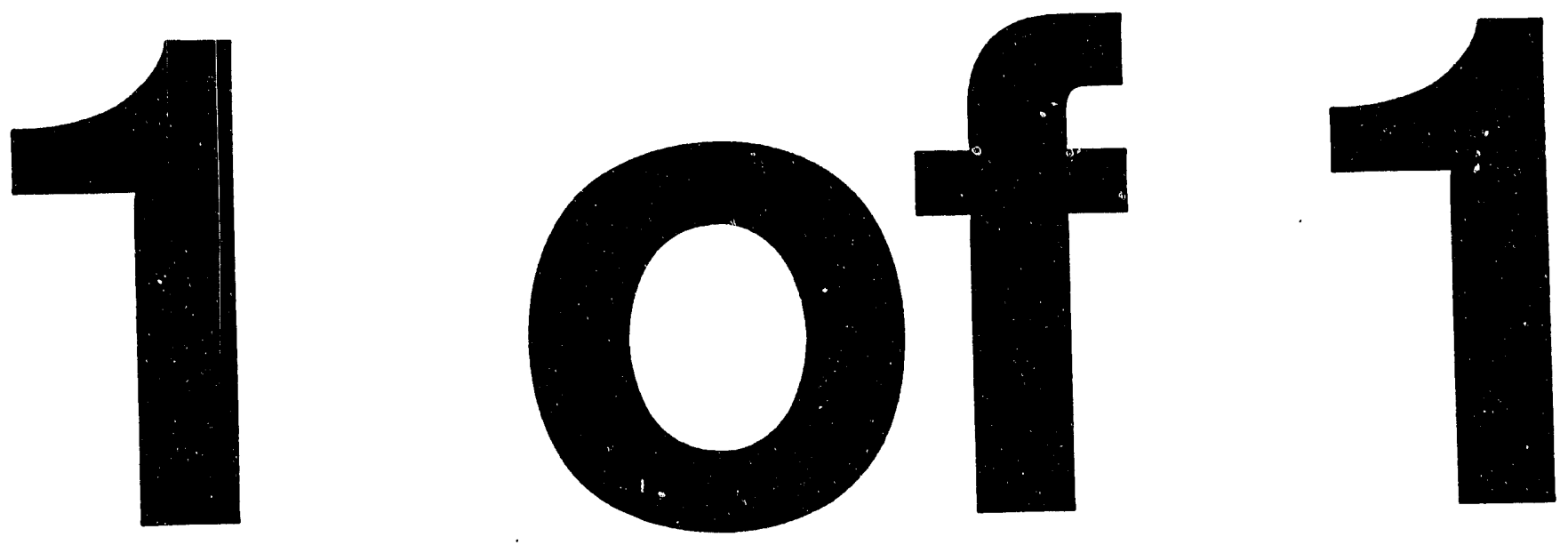


\section{General electraie}

MANFORD ATOMIC PRODUCTE OPERATION - NICMLAND, WABHINGTON

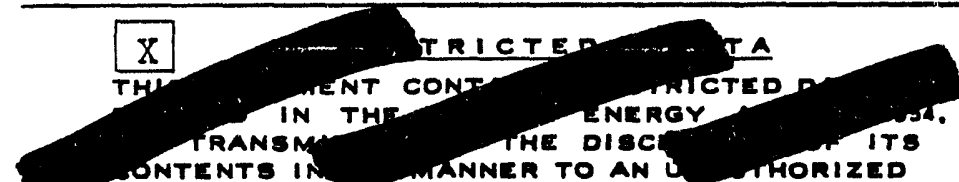

ONTENTB IN

PERSON IS PROHIBITED.
TITLE

\section{CHARACIHER ISTICS OF SPLINVES \\ FOR FINE DISTR IBUTION CONIROL}

OTHER OFPICIAL CLABEIFIED INFORMATION

THIS MATERIAL CONTAINS INFORMATION AFFECTINO THE MATIONAL DEFENEE OF THE UNITED BTATES WITHIN THE MEANING OF THE ESPIONAGE LAWE, TITLE 18, U.8.C., SECS. TOS AND 70A, THE TRANEMISSION OR REVELATION OF WHICH IN ANY MANNER TO AN UNAUTHORIZED PERBON IS PROHIBITED BY LAW.

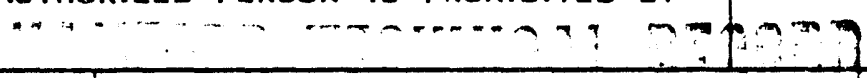

THIS DOCUMENT MUETIMT BELEFT UNATTENDED OK WWHERE AN UNAUTHORIZED PERSON MAK MAVE ACCESS

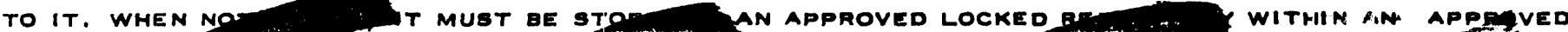
GUARDED A MLE IT IS YOUR MND UNTIL YOU W

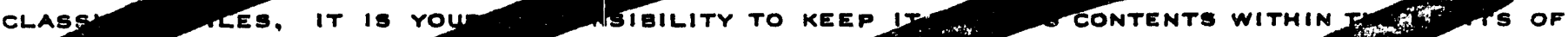
CLAS. SIDENCE IS PROM

TAIN THEM FRE TORIXED PERBON. AUTHOR I8BUING FILE TO SIGN IN THE BP ROVLATED IBSU
ROVID DELOW.

R. D. Carter

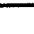




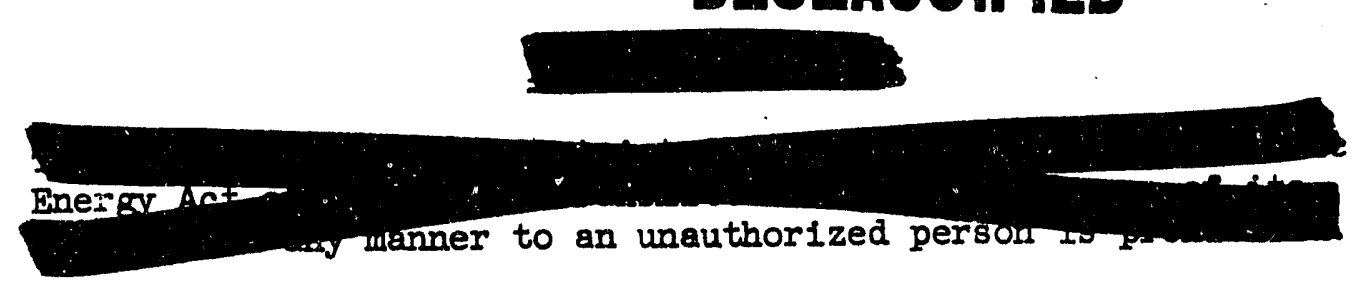

\section{Distribution}

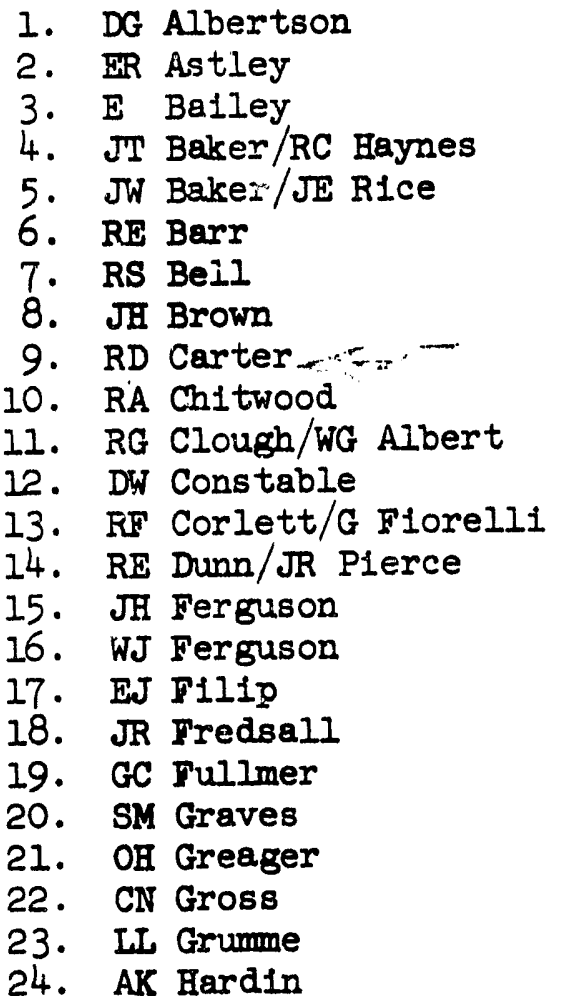

1. DG Albertson

2. $\mathrm{YR}$ Astley

3. E Balley

4. JT Baker/RC Haynes

5. JW Baker/JE R1ce

6. RE Barr

7. RS Beil

8. JH Brown

9. RD Carter

10. RA Chitwood

11. RG Clough/WG Aibert

13. RF Corlett/G Fiorelli

14. RE Dunn/JR Pierce

15. JH Ferguson

16. WJ Ferguson

17. EJ Filip

18. JR TredsalI

19. GC Tullmer

22. CN Gross

24. AK Hardin

\author{
25. RR Henderson \\ 26. JH Hoage \\ 27. CG Hough \\ 28. F Jape \\ 29. EF Jensen \\ 30. AR Kosmata \\ 31. DS Lew1s/RK Wahlen \\ 32. AR Maguire \\ 33. DI Monnie \\ 34. SL Nelson/Go Amy \\ 35. DE Newbrough \\ 36. $R$ Nilson \\ 37. GF Owsley \\ 38. CA Priode \\ 39. RW Reid \\ 40. GJ Rogers \\ 41. DE Sebade \\ 42. SL Stewart \\ 43. $A D$ Vaughn \\ 44. AP Vintiner/II Huffman \\ 45.-46. Extra \\ 47. Record Center \\ 48. 300 File
}

This document classified

by: GCJullmer chamention conound and changed to D.4.

By Autroity of LiA Singdes

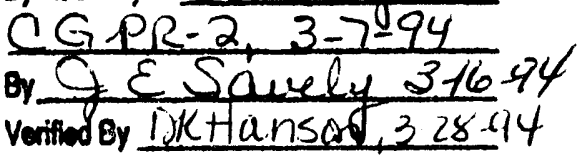

verifid By ikt ianson, 32894

CHARACTERISTICS OF SPLINES FOR FINE DISTRIBUTION CONTROL
This document consists of 14 pages. No. $q$ of copies.

January 29, 1962

\section{INTRODUCTION}

The introduction of poison splines as an operating aid at the Hanford reactors has resulted in an impressive production increase. 1 This increase is mainly due to the effect on startup control and to better equilibrium flux shaping (flattening). In providing sirilclent reactivity effect for startup control, however, present splines sometimes increase rather than decrease flattening and distribution control problems when utilized during

T1/ HW-69979, "Spline-Induced 1960 Production Gains," R.D. Carter, 6-19-61 
equilibrium operation. In addition, belng of constant poison strength along their length, they have limited effectiveness for axial flux control and shaping.

It has therefore been proposed that in addition to the present spline, the use of two other types of splines with finer reactivity effects might be advantageous. These splines are as follows:

1. To reduce large rod movements and increase flattening efficlency - a spline with uniform poison distribution along its length but only about 50 per cent of the present spline reactivity strength (to be noted hereafter as a "grey" spline).

2. To increase axial flux control and shaping - a spline with poison only on the down stream end, no polson on the upotream end (to be noted hereafter as a "half" spline).

\section{SUMMARY AND CONCLUSIONS}

Splines with the following specifications could be used to promote more efficient reactor operation with little or no adverse side effects:

1. Grey Spline - (a) Elght per cent by welght $\mathrm{B}_{4} \mathrm{C}, 0.050$ inches in thickness, 0.300 inches in chord width, or (b) In case that sealing problems inherent with tice above dimensions cannot be solved, 6 per cent by weight $\mathrm{B}_{4} \mathrm{C}, 0.045$ inches in thickness and 0.450 inches in chord width.

2. Half Spline - 15.6 per cent by welght $B_{4} C$, polson length of 19 feet, nonpolson length of 27 feet (these lengths are for experimental purposes only; optimum lengths w11l be determined after further experimentiation), 0.045 inches in thickness, 0.470 inches in chord width.

Other specifications, e.g., weld junctions, solutions to any sealing problems, identification as to type, etc., are beyond the scope of this document.

The splines listed above are calculated to induce a relatively lower rupture rate in the splined charge than in an unsplined charge, and an over-all tube corrosion rate not significantly different than at present. The rate of reactivity change due to burnout of the neutron absorber is compatible with operational requirements.

\section{DISCUSSION}

Following the introduction of the present splines an evaluation of the problems of application indicated that additional spline types were desirable. Specifically, a weaker (or grey) spline was desirable for radial flux shaping during equilibrium operation to reduce overpoisoning of sections of the reactor, and a spline with poison on only half its length was necessary to permit axial flux shaping and control, thus decreasing the tribe rupture potential.

The parameters which define satisfactory spline operation are (not necessarily in orjer of importance):

1. Neutron absorber content (in this sase the boron in $B_{4} C$ ).

2. The physical dimensions. 
3. The change of the reactivity effect due to interactions with the thermal neutron flux (burnout).

4. The effect on tube rupture potential and tube corrosion.

5. Satisfactory sealing with the standard spline seal.

6. Adequate tensile strength.

7. Adequate resistance to bending or kinking during insertion.

The best splines to fit the above criteria were then selected as follows:

Boron Content and Spline Dimensions

To determine the effect of the first two parameters, splines with three different amounts of boron carbide - 5, 10 and 15 per cent - were obtained. Thirty-inch samples of each concentration were then modified either in width or thickness or both. Two samples $=a \mathrm{ch}$ of identical (or as nearly as possible) specifications were then tested. The table below shows the selection of sample specifications.

Table I

Nominal Dimensions of Spline Samples

\begin{tabular}{|c|c|c|c|c|c|c|}
\hline \multirow[b]{2}{*}{ Width Inches } & \multicolumn{6}{|c|}{ Thickness - Inches } \\
\hline & .050 & .045 & .040 & .035 & .030 & .025 \\
\hline $1 / 2$ & $\bar{X}$ & $\bar{X}$ & $\bar{X}$ & $\bar{x}$ & $\mathrm{X}$ & $\bar{x}$ \\
\hline $7 / 16$ & $\bar{X}$ & & & & & \\
\hline $3 / 8$ & $\bar{X}$ & & & $\mathrm{X}$ & & \\
\hline $5 / 16$ & $\bar{x}$ & & & & & \\
\hline $1 / 4$ & $\overline{\mathrm{X}}$ & & & $\bar{x}$ & & \\
\hline
\end{tabular}

Thus, 24 samples for each $\mathrm{B}_{4} \mathrm{C}$ concentration for a total of 72 were tested.

The samples were reduced in width by a normal machining operation. The reduction or thickness was accomplished chemically because of difflculty of reducing the curved siurfaces of the spline.

Since the chemical bath not only reduced the thickness of the samples but also the wiath, the dimensions were not always identical with those on the table. The machining operazion to reduce the width did not always result in a uniform width because of difficulty in. holding the curved spline and the hardness of the $B_{4} C$. Dimensions were measured $\in$ very Iive inches along the spline and then averaged.

The use of a chemical bath in reducing the spline thickness also resulted in pitting of the spline surface. Chemical analysis showed that some $B_{4} C$ was removed from the surface rem sulting in a lower $\mathrm{B}_{4} \mathrm{C}$ density when compared to the spline thickness as checked with $\&$ micrometer. Normalizing the density to that of an untreated sample an equivalent inicieness was obtained. This last value was used in comparing reactivity effects of dimensicn changes. 


\section{DECLLSSFFED}

The 72 spline samples were all tested for reactivity strength in the fanfor $\mathfrak{a}$ Test Reactor (305 Pile). All reactivity values were normalized to the average of the two samples of regular spline specifications. Results are shown in Figure 1.

The desired strength for the grey spline was assumed to be 50 to 60 per cent of a regular spline although this range of values was chosen arbitrarily. Relative reactivity strengths over 60 percent were not consiciered to be enaigs veriation to varrant a different spline type since some variation in strength is possible by not inserting a spline full lengti. LEss reactivity strength required spline specifications that would probabiy not be compe.tisie with mechanical strength or burnout requirements.

On this basis, a new set of curves was drawn wbich showed the variation of thickness, width and $\mathrm{B}_{4} \mathrm{C}$ density necessary to obtain 50 per cent reactivity strength (Figure 2). These curves were obtained from the data in Figure 1 . Since tensile strength is deperider.t, on geometric cross-section, a second family of curves appears on Figure 2 which shows lines of constant geometric cross-section relative to a regular spline.

\section{Burnout Considerations}

The approximate decrease in spline poison strength as a function of the number of operating days was calculated by assuming that a spline has a reactivity strength of a given rimber. of milli-k. This was equated to the proportion of pile neutrons absorbed by the spi.ine." The number of boron atoms in the spline was determined and the per cent burnout was caich" lated from an assumption of pile power level and the number of neutrons released $p \in r$ NWD. The splines were divided into eight regions and the burnout calculated for eack region by a slug-factor-squared welghting.

The rate of decrease of spline strength should not be so rapid that the spline would have to be replaced at frequent intervals. Decreasing spline strength in a reactor at eq1:ilibrium will allow a long term creeping power increase in the splined region. in thr past this has not been noticeable since splinea areas are usually "overpoisoned." Wit a 50 per cent reduction in strength a more rapid burnout rate is involved. Flattering splines are left in the reactor 30 days or longer an appreciable number of times. If we assume that 10 per cent burnout is not limiting, we can use an approximate limit ijr spline operation no more than 10 per cent burnout in 30 operating days.

Regular splines used for total control are uslially assumed to have 10 per cent less than full strength. Burnout of such splines should therefore not be greater than ic per cerit unless burnout is considered in total control calculations.

Reactivity burnout for several spline types were calculated (Figure 3). Specific lata is shown in the table below:

Table II

Burnout Rates

\begin{tabular}{|c|c|c|c|c|c|c|}
\hline \multirow[b]{2}{*}{$T^{2} \mathrm{p}=$} & \multicolumn{4}{|c|}{ Specifications } & \multicolumn{2}{|c|}{ Operating Jays } \\
\hline & $\overline{B_{4} C}$ & Width & Thick. & Rel. Poison Strength & 10\% B.0. & 200.0. \\
\hline $\begin{array}{r}I \\
I I \\
I I I \\
I V\end{array}$ & $\begin{array}{l}15 \\
8 \\
4.25 \\
6\end{array}$ & $\begin{array}{r}.470 \\
.300 \\
.470 \\
.450\end{array}$ & $\begin{array}{l}.050 \\
.050 \\
.050 \\
.045\end{array}$ & $\begin{array}{l}1.00 \\
0.50 \\
0.50 \\
0.585\end{array}$ & $\begin{array}{l}73 \\
38 \\
23 \\
27\end{array}$ & $\begin{array}{r}134 \\
30 \\
45 \\
53\end{array}$ \\
\hline
\end{tabular}
Type I is a regular spline. Types II, III and IV are variations of a grey spiine, Irp'
numbers have no significance except to permit easier identification withir this doculant.) 







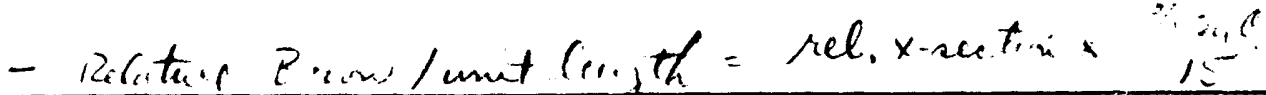

15

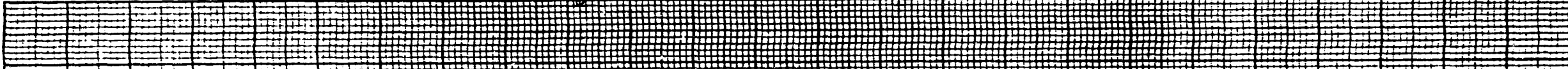

10 W

1 + W.

o.



5

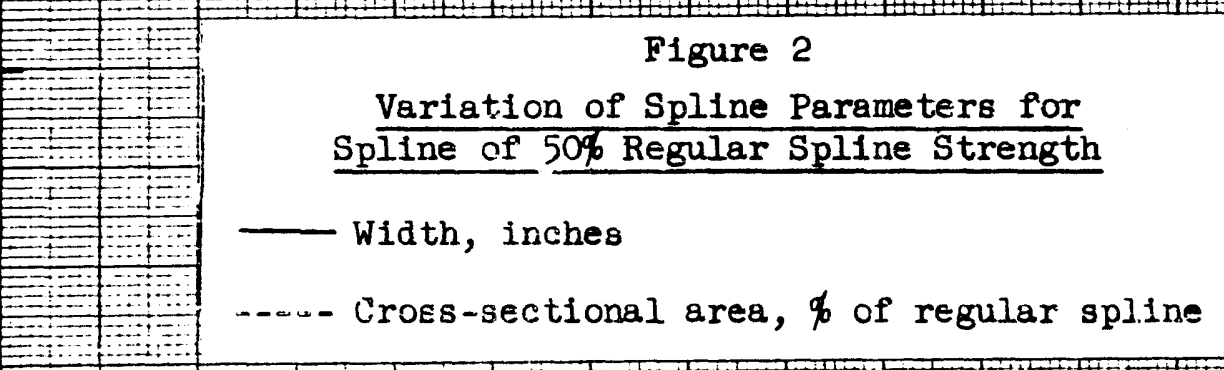

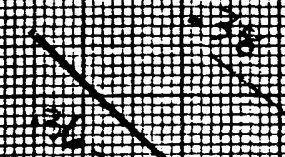

+

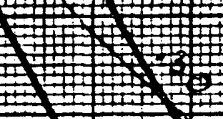

-
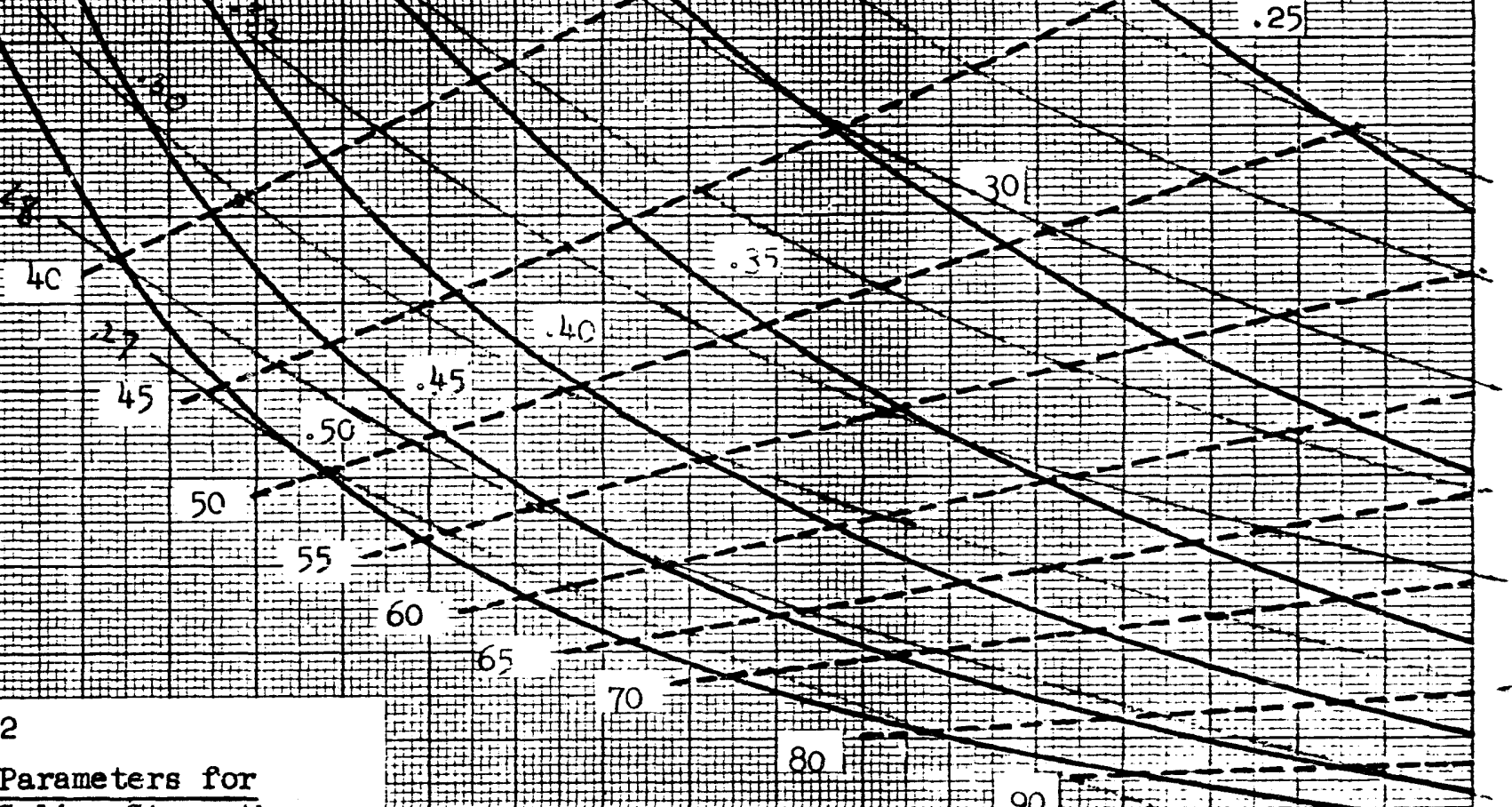

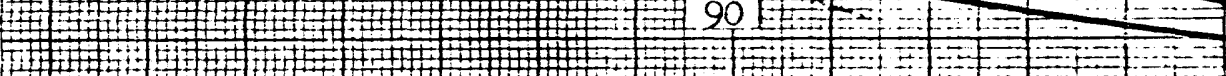

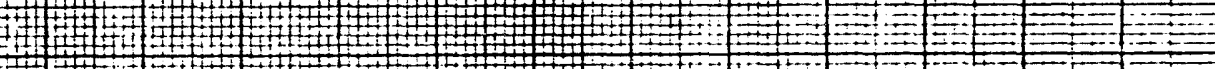
DELLSFFED 2 Spline Thickness, Inches 


\section{EW - 72497 \\ Dage 7

OECLASSIFIED

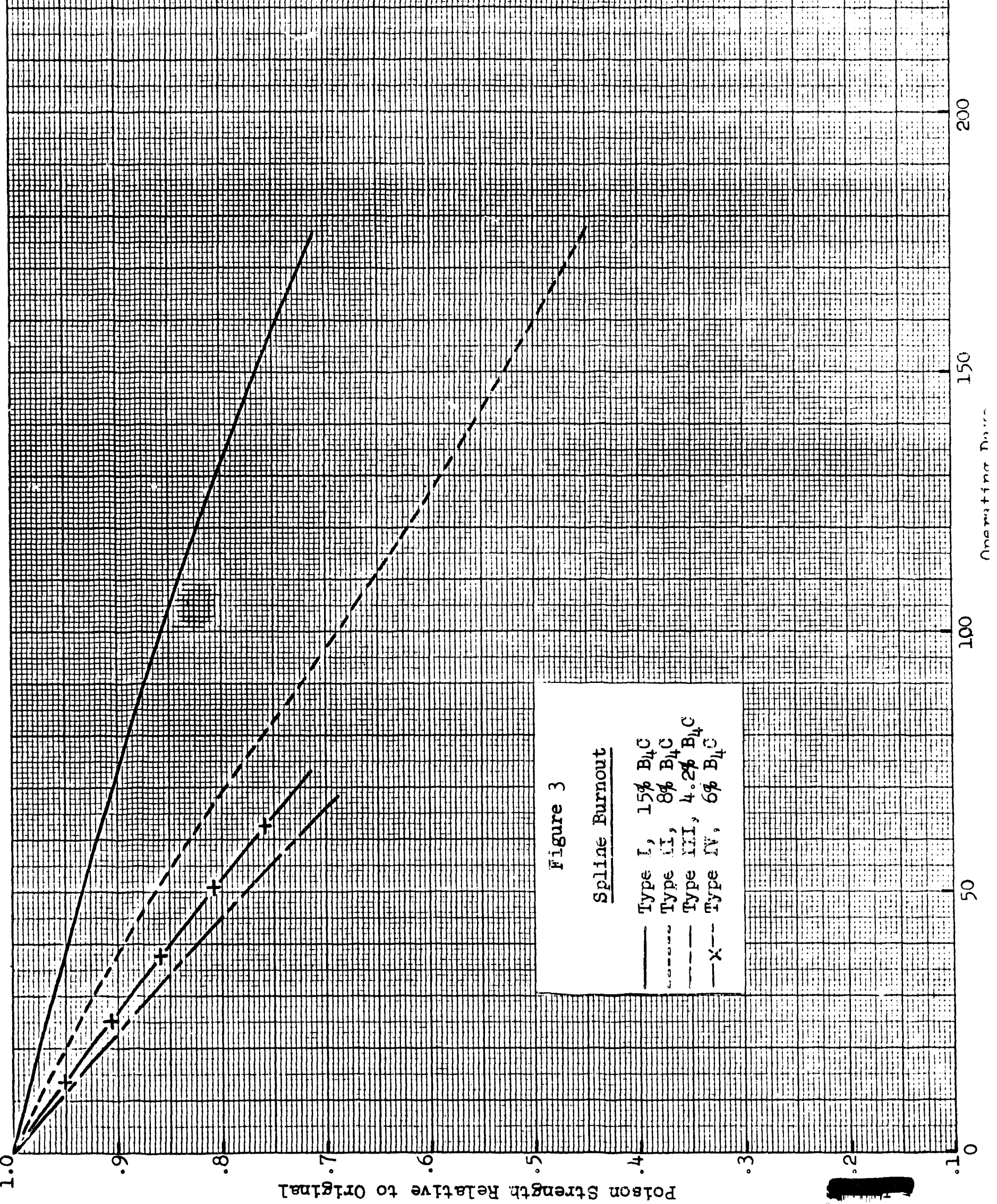


Type II was selected as the spline having 50 per cent of strength of the regular spline (see Figure 2) and the best combination of tensile strength, resistance to buckling, low burnout rate and low flow resistance. However, this spline is not compatible with the present spline seals. Unless some provision can be made to ensure adequate sealing it may not be acceptable.

Type III is a spline having 50 per cent of the strength of the original spline and the same dimensions. The amount of $\mathrm{B}_{4} \mathrm{C}$ in this spline is low (4.25 per cent) and the burnout rate is relatively rapid. Ten per cent burnout occurs at 23 operating days compared to 38 days :or Type II and is significantly faster than the limiting conditions selected above.

TJpe IV Is a spline having the minimum dimensions compatible with good spline sealing, .450 inches thick and .045 inches wide. To decrease the burnout rate the amount of toron was increased by selecting a relative reactivity strength close to .60 . Since six per cent B4C gave a relative strength of .585 this composition was used. With this spline 10 per cent burnout occurred at over 27 operating days which is close to the 30 days previously selected as a limit. This spline could probably be used as an alternate to Type II.

\section{Mechanical Properties}

Tenslle strength of a spline should be proportional to the geometric cross-section. Therefore from the standpoint of greatest tensile strength a spline having the greatest geometric cross-section is required. Also, for a given reactivity strength, greater boron content per unit length results in a slower burnout rate. Therefore it is desirable from both the standpoint of tensile strength and burnout to obtain the greatest cross-section for a given boron content and reactivity strength.

If we assume that for 50 per cent reactivity strength about eight per cent $B_{4} C$ is the minimum desirable concentration from the standpoint of burnout rate, from Figure 2 we find that for a spline of 50 per cent reactivity strength and no dimension greater tian the regular spline the specifications are:

$\begin{array}{ll}\text { Thickness } & -0.050 \text { inches } \\ \text { Width } & -0.30 \text { inches } \\ \text { \% } \mathrm{B}_{4} \mathrm{C} \text { by welght }-8\end{array}$

This results in a spline having a relative geometric cross-section of about 64 per cent that of the present splines which would indicate a relative tensile strength of 64 per cent. However, tensile tests $/ 2$ indicate a slight increase in strength as the $B_{4} \mathrm{C}$. density decreases. Therefore the relative strength would probably be in the range of 65 to 70 per cent.

Resistance to buckling of a spine with the above dimensions should be more than adequate Tests by $W$. Dalos $/ 3$ indicate that a spline with the above dimensions would bucikle at about 55 to 65 pounds force on the handle of the spline inserter. The normal spline insertion force is 10-20 pounds and the normal maximum is 40 pounds.

\section{Sealing}

The tests by W. Dalos also showed that sealing was not adequate for spline widths less than about $7 / 16$ inch or thicknesses less than about .045 inch with some possible reservations because the tested samples did not all have the same edge finish as the reguiar

T2/ Private Comunication from w. Dalos, 9-29-61

$/ 3 /$ Ibid 


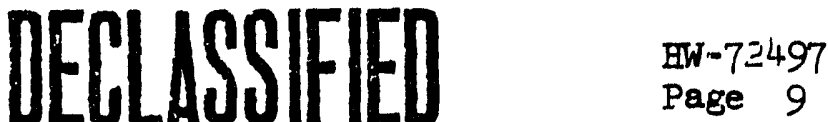

spline. However, it is belleved possible to obtain an adequate seal with splines of smaller width than $7 / 16$ inch by the use of plastlc inserts, use of a full sized end piece, or redesign of the seal. Therefore the spline seal problem may not be restrictive.

\section{Efect on Slug Ruptures}

The expected number of ruptures in a tube is a function of local surface temperature, power and exposure. The local temperature is correlated to the bulk outlet temperature by:

$$
r=\frac{\Delta T_{i}}{\Delta T_{B}}
$$

where $T_{1}$ is the local temperature and $T_{B}$ is the tube outlet temperature.

The rupture rate is assumed equal to $\mathrm{k} P 3.3 \mathrm{~T}_{1} 8.7 \mathrm{E}^{5}$ where $\mathrm{P}$ is the power and $\mathrm{E}$ is the exposure. (Since power and therefore exposure are assumed to be constant around the fuel element, $P$ and $E$ may represent tube power and exposure.) $E$ is also Pt, where $t$ is the time; therefore,

$$
R=k P^{8.3} T_{i}^{8.7} t^{5}
$$

but since $\mathrm{T}_{i}=r \Delta \mathrm{T}_{\mathrm{B}}$

$$
R=k P^{8.3}\left(r \Delta T_{B}\right)^{8.7} t^{5}
$$

In the normal state of affairs the reduction in rib height and the corrosion of the tube wall as the tube grows older result in an increase in the local temperature for the bottom of the tube and decrease for the top; so the highest $r$ value is generally assumed to be adequate. However, for the case of a spline insertion the local temperature in the top may not decrease, and the bottom temperature and the bulk outlet temperature will increase resulting in a decrease in the $r$ value at the top. This results in an erroneous calculation of the rupture rate increase unless the top and bottom are considered separately. Therefore we must write:

$$
\begin{aligned}
& R=k^{\prime}\left[p^{8.3}\left(r_{Q} \Delta T_{B}\right)^{8.7} t^{5}+P^{8.3}\left(r_{b} \Delta T_{B}\right)^{8.7}\right] t^{5} \\
& =k^{\prime}(P)^{8.3}\left(\Delta T_{B}\right)^{8.7}\left[r_{a}^{8.7}+r_{b}^{8.7}\right] t^{5}
\end{aligned}
$$

where $a$ and $b$ represent the highest $r$ values in the upper and lower halves of the tube respectively.

If a spline insertion results in a higher rupture rate, then the worst case is for the spline inserted the entire life of the charge. The relative rupture rate, $R_{r}$ between a charge without a spline and ore with a spline will then be:

$$
R_{r}=\left(\frac{P^{\prime}}{P}\right)^{8.3}\left(\frac{\Delta T_{b}^{\prime}}{\Delta T_{B}}\right)^{8.7}\left[\left(\frac{\left(r_{a^{\prime}}\right)^{8.7}+\left(r_{b^{\prime}}\right)^{8.7}}{\left(r_{a}\right)^{8.7}+\left(r_{b}\right)^{8.7}}\right]\right.
$$

where the primes represent the values with a spline inserted. 
From previous work $/ 4 /$ we can determine the changes around the annulus with two different types of splines inserted in a new process tube, a regular spline and a twenty mil thick spline with no boron and hence no reactivity effect. From tests at $B, D$, $D R$ and $F$ reactors it was determined that for the insertion of a regular spline the flow decrease was 5 per cent and the decrease in tube power relative to the surrounding tubes was about 7.I per cent. Assuming that a regional power decrease of 4 per cent was normally desired (instead of the initial decrease of about 7 per cent) and that this was maintained by proper control rod adjustment we find that the over-all decrease in spline tube power is about 12.3 per cent.

The values of $r$ change as the ribs wear and the process tube corrodes. Data from Ferguson's test was normalized to curves showing the change in $r_{a}$ and $r_{b} / 5 /$ with tube corrosion index. Ferguson's data involved a new tube. It was assumed that the data obtained Irom BW-71206 was representative. The data for the $r$ values with no spline in the tube was normalized to the curves, and the data for spline insertion was made relative to 1t. It was assumed that the shapes of the curves of $r_{a}$ and $r_{b}$ were 1dentical with increasing corrosion index to the curves without splines. Aamittedly the data is meager but it is applied in a logical manner.

Assuming that the addition of a polsor spline changes the power uniformly over a slug and that the incremental changes in power and temperature for columns containing grey splines are proportional to the incremental changes in poison strength within those parameters represented by the regular spline and a nonpoisonous spline, we may obtain the data in Table III.

Table III

Relative Rupture Rates and Associated Data

\begin{tabular}{|c|c|c|c|c|c|c|c|c|}
\hline pline Type & $=$ & $I$ & $I I_{0}$ & $\mathrm{II}_{70}$ & II20 & IV & V & VI \\
\hline $\begin{array}{l}\mathrm{oB}_{4} \mathrm{C} \\
\text { Thickness } \\
\text { Width } \\
\text { \% Burnout } \\
\text { Rel. React. }\end{array}$ & 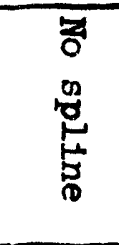 & $\begin{array}{l}15 \\
0.050 \\
0.50 \\
0 \\
1.000\end{array}$ & $\begin{array}{l}8 \\
0.050 \\
0.300 \\
0 \\
0.50\end{array}$ & $\begin{array}{l}8 \\
0.050 \\
0.300 \\
10 \\
0.45\end{array}$ & $\begin{array}{l}8 \\
0.050 \\
0.300 \\
20 \\
0.40\end{array}$ & $\begin{array}{l}6 \\
0.045 \\
0.450 \\
0 \\
.585\end{array}$ & $\begin{array}{l}0 \\
0.020 \\
0.470 \\
0 \\
0\end{array}$ & $\begin{array}{l}0 \\
0.050 \\
0.470 \\
0\end{array}$ \\
\hline $\begin{array}{l}\text { Rel. Tube Flow } \\
\text { Rel. Tube PWr. } \\
\text { Rel. Out } \Delta \mathrm{T}\end{array}$ & $\begin{array}{l}1.000 \\
1.000 \\
1.000\end{array}$ & $\begin{array}{l}.950 \\
.877 \\
.923\end{array}$ & $\begin{array}{l}.952 \\
.938 \\
.985\end{array}$ & $\begin{array}{l}.952 \\
.944 \\
.992\end{array}$ & $\begin{array}{l}.952 \\
.950 \\
.998\end{array}$ & $\begin{array}{l}.950 \\
.928 \\
.977\end{array}$ & $\begin{array}{l}.955 \\
1.000 \\
1.047\end{array}$ & $\begin{array}{l}.950 \\
1.000 \\
1.053\end{array}$ \\
\hline $\begin{array}{l}\text { New Tube: } \\
r_{a} \\
r_{b} \\
R_{r}\end{array}$ & $\begin{array}{r}1.072 \\
.925 \\
1.000\end{array}$ & $\begin{array}{r}1.018 \\
1.005 \\
.158\end{array}$ & $\begin{array}{r}1.018 \\
.991 \\
.461 \\
\end{array}$ & $\begin{array}{r}1.018 \\
.991 \\
.516\end{array}$ & $\begin{array}{r}1.018 \\
.991 \\
.579\end{array}$ & $\begin{array}{r}1.018 \\
1.005 \\
.415\end{array}$ & $\begin{array}{l}1.018 \\
.984 \\
1.30\end{array}$ & $\begin{array}{l}1.018 \\
1.005 \\
2.48\end{array}$ \\
\hline $\begin{array}{l}0 \text { mil Tube: } \\
r_{a} \\
r_{b} \\
R_{r}\end{array}$ & $\begin{array}{r}.981 \\
1.086 \\
1.000\end{array}$ & $\begin{array}{r}.925 \\
1.164 \\
.248\end{array}$ & $\begin{array}{r}.925 \\
1.152 \\
.702\end{array}$ & $\begin{array}{r}.925 \\
1.152 \\
.786\end{array}$ & $\begin{array}{r}.925 \\
1.152 \\
.881\end{array}$ & $\begin{array}{r}.925 \\
1.164 \\
.650\end{array}$ & $\begin{array}{l}.925 \\
1.145 \\
1.94\end{array}$ & $\begin{array}{l}.925 \\
1.164 \\
2.32\end{array}$ \\
\hline
\end{tabular}

T4/ BW-71206, "Test of Nonpoisonous Splines," J. H. Fergison, 9-29-61

/5/ Private commication from C. G. Hough 
The data indicate that the rupture potential for the column containing a full length grey spline of proposed dimensions is less, up to at least 20 per cent $B_{4} C$ burnout, than with no spline inserted. Therefore we should be able to use the proposed grey spline, dependent upon a satisfactory solution to the spline seal problem, without penalty.

The minimum permissible reactivity strength may be calculated by setting $R_{r}$ equal to 1.000 which implies no increase in rupture rate of a splined tube over a nonsplined tube. If we then assume a full-sized spline and a $40 \mathrm{mll}$ tube wall thickness as the worst case, we can assume conservatively values of $\mathrm{r}_{\mathrm{a}}$ and $\mathrm{rb}$ corresponding to the 15 per cent $\mathrm{B}_{4} \mathrm{C}$ spline.

Since the incremental changes in tube powers and temperatures are proportional to the reacti,ity effect of a spline we can then show that for $R_{r}$ equal to unity the minimum reactivity of a full size spline is slightly less than 40 per cent of a regular spline. If therefore we have a relative spline strength of no less than $.40 \mathrm{with}$ any combination of boron content and poison burnout and with any flow restriction equal to or less than that for the regular spilne, we can say that such a combination is not restrictive from the standpoint of fuel muptures.

The half-spline should use the maximum possible polson strength in the downstream section and no poison in the upstream section to obtain the greatest skewing effect. If we assume that the regular spline has the greatest practical poison strength, the poison end of the half-spline will be the same composition as the regular spline. If the upstream end is fuil sized but hos no poison, from Table II we can obtain $R_{r}$ values for each section. From the Nola-2 767 Plux traverse program we can obtain flux traverse data which show a mupture potential for each siug in a charge. Using these data, we can calculate (Fig. 4) the variation in rupture potential of a tube with a half-spline inserted relative to one without a half-spline as a function of the length of the nonpoison section in slug lengths (the downstream section containing poison). Curve I assumes that originally the flux was a cosine distribution and that the insertion of a half-spline of the above composition, but of any combination of polson and nonpoison lengths, results in the maximum flux being skewed five slugs upstream of the centerline and peaked 8.5 per cent above a cosine. Curve I shows that the relative rupture potential would be only .9 that of the cosine for a halp-spline whose nonpoison section length was up to half the length of the active zone. Curve II assumes the flux skewed two slugs downstream and peaked 5.8 per cent above a cosine prior to the insertion of a half-spline and that insertion of a half-spline resuits in no change after insertion. The rupture potential relative to a cosine is initiaily 1.88 (prior to spline insertion). With no change assumed in the Plux peak iocation, the nonpoison section inserted to 16 slug lengths results in a rupture potential only 48 per cent of the original.

Therefore in neither extreme case would a half-spline result in potential loss as iong as the nonpoison section is limited to half the active zone length. A tube with a 40 mil wall thickness was selected as the extreme case of a worn tube in which a spline is likely to be inserted, because of the difficulty of inserting splines in older tubes.

The length of the initial group of half-splines to be used for experimentai purposes can be determined from the various reactor dimensions. The poison section should be the equivalent of two-thirds tine $K$ Reactor charge length to allow determination of the optimum length for the poison section. This is 19 feet. The ends may then be cut to the desired size. The nonpoison section should preferably be short enough that this section cannot be inserted deeper than the midale of a given slug column, requiring different lengths for the older reactors and $K$ reactors. The initial experimental group of splines will be under the close control of a responsible engineer in the Operational Physics Sub-Section.

76/ HW-69486, Rev. 1, "The Nola-2 Code," G. F. Bailey, 10-31-61 


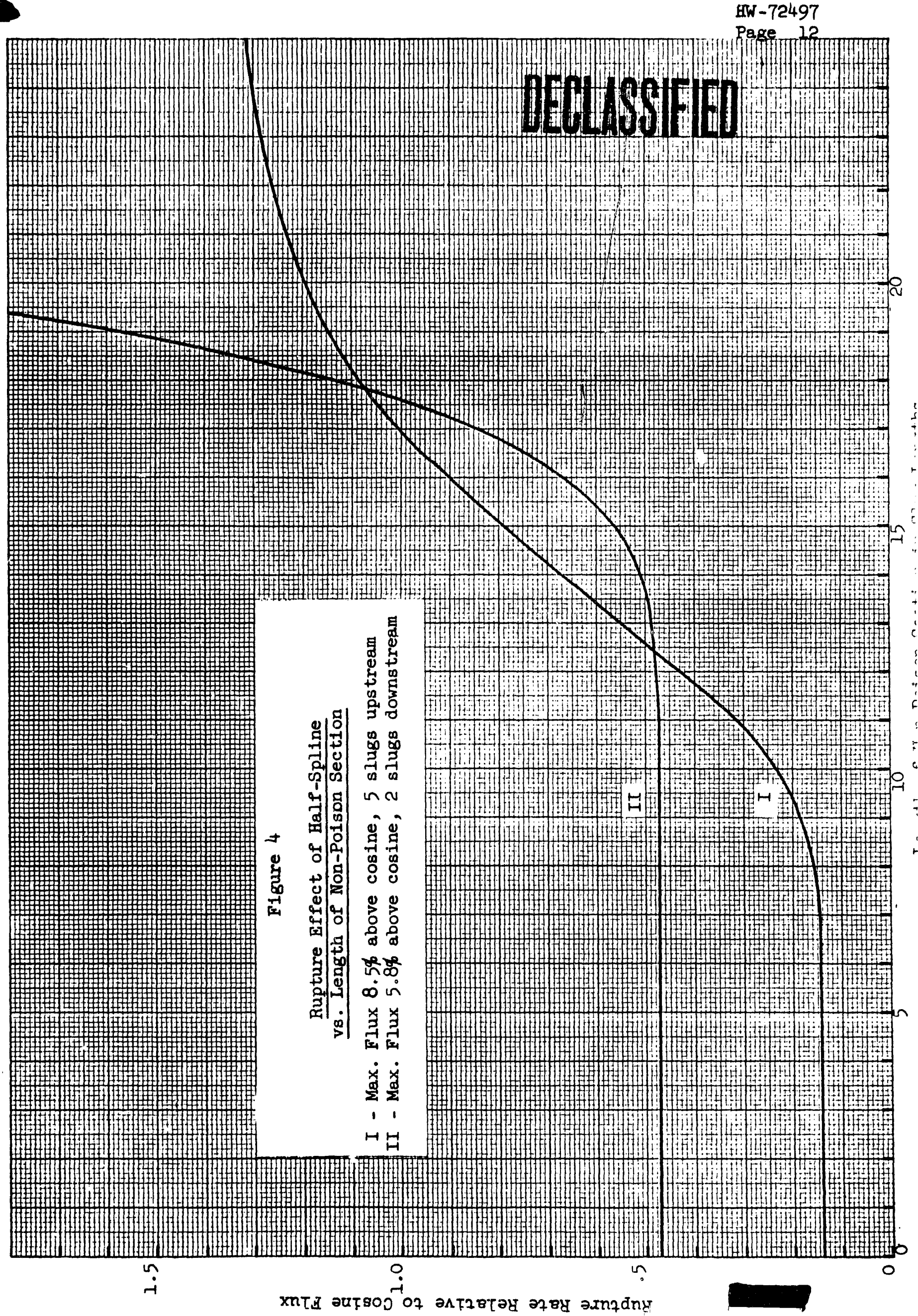


In order to simplify initial experimental usage under closely observed conditions a single type of half-spline should be obtained whose upstream end is the longest required (27 reet for a $\mathrm{K}$ reactor including one foot outside the cap). The splines will be reduced to the desired dimensions prior to use.

In addition a $45 \mathrm{mll}$ thick spline is desirable rather than a $50 \mathrm{mil}$ spline since it is felt that same insertion problems may be alleviated with slightly thinner splines.

\section{Tube Corrosion}

Increased process tube corrosion could occur as the result of the long-term irradiation of a spline if there were an increase in local water temperature. Increased local water temperature will result if flow reduction is greater than power reduction.

The local corrosion rate of a process tube may be described approximately by:

$$
\mathrm{CR}=\mathrm{ke} \cdot 057\left(\mathrm{~T}_{1}+\mathrm{r} \Delta \mathrm{T}_{\mathrm{B}}\right)
$$

where $T_{i}$ is the inlet temperature, $\left(T_{i}+r \Delta T_{B}\right)$ is the outlet tenperature corrected to locai conditions and the other terms are as previousiy defined.

This equation is not exact but conforms to: the model presently used.

The relative corrosion rate between a splined tube and a nonsplined tube may be written as:

$$
\begin{aligned}
& \text { Rel. } G R=\frac{k e^{.057\left(T_{1}+r^{\prime} \Delta T_{B}{ }^{\prime}\right)}}{k e^{.057\left(T_{1}+r \Delta T_{B}\right)}} \\
& =e^{\left..057^{\prime} r^{\prime} \Delta T_{B}{ }^{\prime}-r \Delta T_{B}\right)} \\
& =e^{.057 \mathrm{r} \Delta \mathrm{T}_{\mathrm{B}}}\left(\frac{\mathrm{r}^{\prime}}{\mathrm{r}} \frac{\Delta \mathrm{T}_{\mathrm{B}^{\prime}}}{\Delta \mathrm{T}_{\mathrm{B}}}-1\right)
\end{aligned}
$$

\begin{tabular}{|c|c|c|c|c|c|c|c|c|}
\hline Spline Type & $I$ & $I I_{0}$ & $\mathrm{II}_{10}$ & $I I_{20}$ & III & IV & V & VI \\
\hline $\begin{array}{l}\text { New Tube: } \\
\text { Top } \\
\text { Bottom }\end{array}$ & $\begin{array}{r}.47 \\
1.01\end{array}$ & $\begin{array}{r}.68 \\
-.34\end{array}$ & $\begin{array}{r}.70 \\
1.39\end{array}$ & $\begin{array}{r}.73 \\
1.44\end{array}$ & $\begin{array}{r}.68 \\
1.47\end{array}$ & $\begin{array}{r}.64 \\
1.38\end{array}$ & $\begin{array}{r}.97 \\
1.83\end{array}$ & $\begin{array}{l}1.00 \\
2.14\end{array}$ \\
\hline $\begin{array}{l}40 \text { Mil Thibe: } \\
\text { Top } \\
\text { Bottom }\end{array}$ & $\begin{array}{l}.48 \\
.93\end{array}$ & $\begin{array}{r}.68 \\
1.32\end{array}$ & $\begin{array}{r}.70 \\
1.39\end{array}$ & $\begin{array}{r}.72 \\
1.44\end{array}$ & $\begin{array}{r}.68 \\
1.42\end{array}$ & $\begin{array}{r}.64 \\
1.34\end{array}$ & $\begin{array}{r}.93 \\
1.40\end{array}$ & $\begin{array}{r}.98 \\
2.25\end{array}$ \\
\hline
\end{tabular}

Using the data in Table II the following relative corrosion rates were calculated:

Table IV

Relative Corrosion Rates, $\Delta T_{B}=100^{\circ} \mathrm{C}$

771 HW-60123, "Forecast Routine Process Tube Replacements FY 1960 to 1964, App. A," E.F. Falrweather, et al, 4-22-59 


\section{DECLLSSFFIED}

HW-72947

Page 14

Since tube corrosion in the bottom of the tube is most limiting to tube life only the relative values for this region need be considered. The data indicate no significant increase in tube corrosion rates for the regular spline and probably a slight decrease.

For the grey splines an increase of 30 to 40 per cent 1 is indicated. However, it must be remembered that these numbers represent only instantaneous rates. About ten grey splines would be expected to be in the reactor at any one time and the tubes affected would change with the varlation of local reactivity requirements. Since there are well over 100 tubes with spline caps on the reactor it should be presumed that grey splines would be inserted in a given tube for only about 10 per cent of the tube life, resulting in an actuai increase in corrosion rates of closer to 3 to 4 per cent rather than 30 to 40 per cent. Variation of spline cap locations and the necessary use of regular splines rather than grey splines in a number of cases should linit further any increase in corrosion rates of tubes used for spline insertion.

Spline $V$ is intended for use as a flux traverse device and would have little effect on tiabe life because of a 15 minute residence time.

Spiine VI wouid be used only as the upstream part of a half-spline. The effect on thibs corrosion rates would be less than that shown in Table IV for the same reasons as given for the grey splines. A further decrease would result from the fact that the upstream section of a half-spline would be in a maximum water temperature of about haif the $\Delta \mathrm{T}_{\bar{B}}$ used in tine calculations.

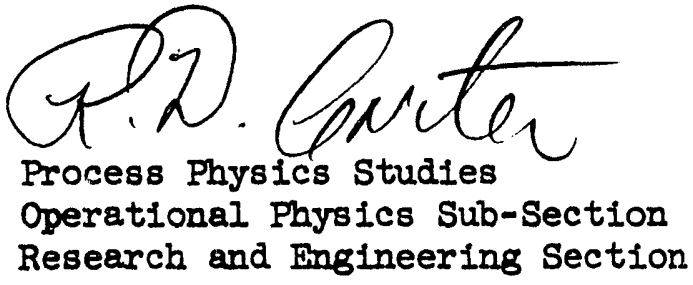

RD Carter:gs 

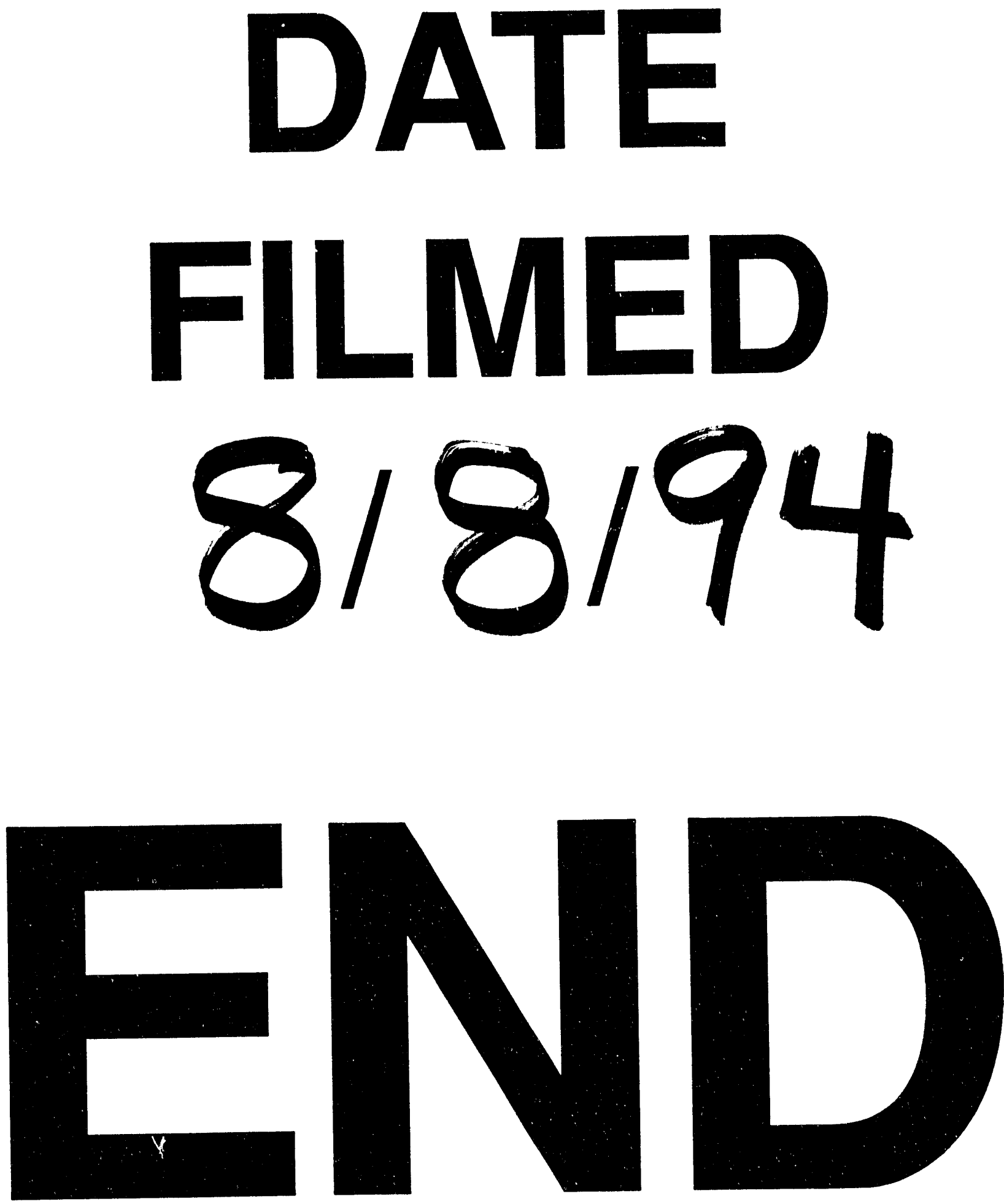
